Article

\title{
Zero Voltage Switching Condition in Class-E Inverter for Capacitive Wireless Power Transfer Applications
}

\author{
Fabio Corti ${ }^{1, *(\mathbb{D})}$, Alberto Reatti ${ }^{1, *(\mathbb{D})}$, Ya-Hui $\mathrm{Wu}^{2}{ }^{2}$, Dariusz Czarkowski ${ }^{2}$ and Salvatore Musumeci $^{3}$ (D) \\ 1 Department of Information Engineering, DINFO, Università degli Studi di Firenze, 50129 Florence, Italy \\ 2 Department of Electrical and Computer Engineering, NYU Tandon School of Engineering, \\ New York, NY 11201, USA; yhw259@nyu.edu (Y.-H.W.); dc1677@nyu.edu (D.C.) \\ 3 Energy Department, PEIC, Politecnico di Torino, 10129 Torino, Italy; salvatore.musumeci@polito.it \\ * Correspondence: fabio.corti@unifi.it (F.C.); alberto.reatti@unifi.it (A.R.)
}

Citation: Corti, F.; Reatti, A.; Wu, Y.-H.; Czarkowski, D.; Musumeci, S. Zero Voltage Switching Condition in Class-E Inverter for Capacitive Wireless Power Transfer Applications. Energies 2021, 14, 911. https:// doi.org/10.3390/en14040911

Academic Editor:

Pedro Roncero-Sanchez

Received: 28 December 2020

Accepted: 4 February 2021

Published: 9 February 2021

Publisher's Note: MDPI stays neutral with regard to jurisdictional claims in published maps and institutional affiliations.

Copyright: (c) 2021 by the authors. Licensee MDPI, Basel, Switzerland. This article is an open access article distributed under the terms and conditions of the Creative Commons Attribution (CC BY) license (https:// creativecommons.org/licenses/by/ $4.0 /)$.

\begin{abstract}
This paper presents a complete design methodology of a Class-E inverter for capacitive wireless power transfer (CWPT) applications, focusing on the capacitance coupling influence. The CWPT has been investigated in this paper, because most of the literature refers to inductive power transfer (IWPT). However, CWPT in perspective can result in lower cost and higher reliability than IWPT, because it does not need coils and related shields. The Class-E inverter has been selected, because it is a single switch inverter with a grounded MOSFET source terminal, and this leads to low costs and a simple control strategy. The presented design procedure ensures both zero voltage switching (ZVS) and zero derivative switching (ZDS) conditions at an optimum coupling coefficient, thus enabling a high transmission and conversion efficiency. The novelties of the proposed method are that the output power is boosted higher than in previous papers available in the literature, the inverter is operated at a high conversion efficiency, and the equivalent impedance of the capacitive wireless power transfer circuit to operate in resonance is exploited. The power and the efficiency have been increased by operating the inverter at $100 \mathrm{kHz}$ so that turn-off losses, as well as losses in inductor and capacitors, are reduced. The closed-form expressions for all the Class-E inverter voltage and currents waveforms are derived, and this allows for the understanding of the effects of the coupling coefficient variations on ZVS and ZDS conditions. The analytical estimations are validated through several LTSpice simulations and experimental results. The converter circuit, used for the proposed analysis, has been designed and simulated, and a laboratory prototype has been experimentally tested. The experimental prototype can transfer $83.5 \mathrm{~W}$ at optimal capacitive coupling with operating at $100 \mathrm{kHz}$ featuring $92.5 \%$ of the efficiency, confirming that theoretical and simulation results are in good agreement with the experimental tests.
\end{abstract}

Keywords: capacitive wireless power transfer; Class-E inverter; resonant converter; zero voltage switching

\section{Introduction}

Over the last few years, wireless power transfer (WPT) has increasingly attracted industry and academia attention, and it is utilized in an increasing number of applications. One of the WPT systems main applications is that of battery charging in biomedical implants [1], electric vehicle wireless charging [2-4], mobile phone and electronic consumers [5,6], moving robots [7], and wireless sensors [8,9]. This is due to advantages introduced by this technology; some of them are as follows: WPT allows the product to be completely sealed, making it waterproof; it facilitates the charging process avoiding the use of bulky power cables; and finally, it allows the product life to be increased. By eliminating the physical limitations of connectors, like mating cycles and corrosion of contacts, wireless power transfer results in more robust products [10].

The capacitive wireless power transfer (CWPT) is a recent alternative to the more investigated inductive wireless power transfer (IWPT) [11-13]. A schematic block representation of a CWPT system is shown in Figure 1. The architecture is similar to an IWPT 
system [14,15], but coupling among the primary and secondary sides is based on the electric field, rather than the magnetic field. A primary inverter impresses a high-frequency alternative voltage to the transmission circuit. An electric field-based power transfer between metallic plates without a direct electrical connection is achieved. In a wireless charging application, requiring the load to be supplied by a DC voltage, the power received from the secondary plates is rectified to supply a load. Compared to an IWPT system, a CWPT system has several advantages, such as:

- $\quad$ Lower cost: CWPT does not need expensive magnetic cores and Litz wires to reduce the parasitic resistance due to skin and proximity effects $[15,16]$. The power is transferred through low-cost metallic plates. Because of this characteristic, a CWPT also results in smaller volumes and weights than IWPT.

- Higher stability in metallic surrounding environment: metallic materials block an inductor magnetic flux transmitted between two coils. Additionally, eddy currents induced by a changing magnetic field generate heat and increase the power losses and safety concerns.

- Capability to transfer power through metal barriers thanks to the coupling capacitive effect.

- Less leakage flux leading to less electromagnetic interference (EMI): an IWPT system uses a magnetic field whose flux tends to propagate in any direction; in contrast, a CWPT system uses an electrical field that traps energy between metal plates $[17,18]$.

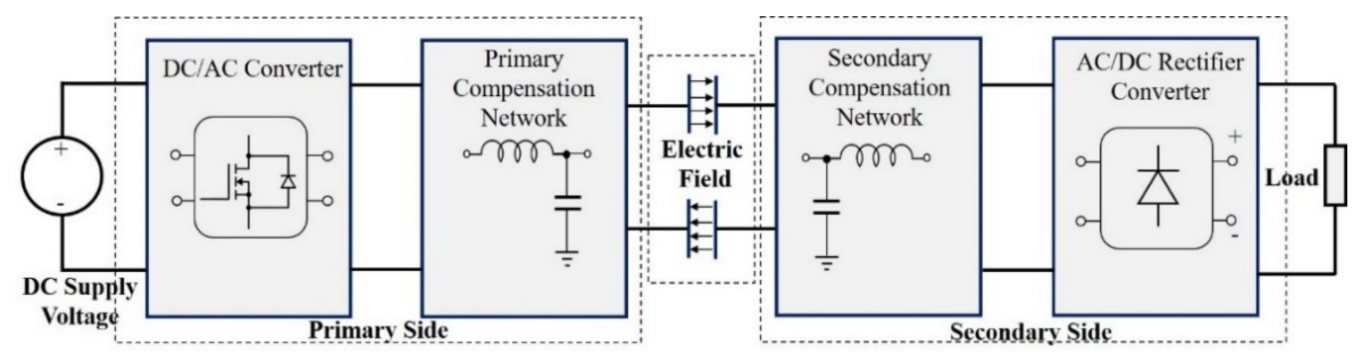

Figure 1. Block diagram of a general capacitive wireless power transfer system.

To capitalize on these advantages over IWPT, several research projects have recently started to study and improve CWPT [10].

In a CWPT system, the metal plates are electrically coupled through the air, leading to a coupling capacitance of a few picofarads. To reduce the equivalent capacitive reactance of the system, the converter must be operated at a high switching frequency, and this results in high switching losses in hard switching converters. Wide bandgap (WBG) devices represent a suitable solution to transfer a high power at a high switching frequency, but they also result in a significant cost increase and EMI problems [18].

A suitable solution to overcome these problems is constituted by the utilization of soft-switching converters, e.g., resonant converters, where LC networks are utilized to reduce switching power losses due to voltage and current crossing during the switch turn-on and turn-off. The zero voltage switching (ZVS) condition is usually referred to a voltage equal to zero across the switching devices [19] and its turn-on, and this reduces to zero the turn-on losses. In a power MOSFET, turn-on loss is due to the dissipation of the energy stored in the MOSFET output parasitic capacitance, and this energy is reduced to zero when the voltage across the capacitance is zero.

The Class $E$ converter is appropriate for a high-frequency operation, because it can achieve ZVS, and under optimum operation, the voltage derivative is also zero. This last condition is known as the zero derivative switching (ZDS) condition, and it plays a key role to reduce EMI interference [20]. The total harmonic distortion (THD) of the output voltage is very small. For this reason, this converter is one of the best solutions for the realization of inverters with a rated power of up to a few hundred Watts. Additionally, being made up from one single MOSFET, it allows the reduction of the converter cost and dimension 
and increases its reliability. Moreover, this circuit results in an easy gate drive requirement, because it is composed of a grounded single switch. In this converter, the switch ZVS turns on and high efficiencies are possible if the component values of the resonant circuit are properly chosen [21-23].

For this reason, several studies have been made to use the Class-E topology for capacitive WPT. In [24], a capacitive Class-E inverter for rotating applications has been presented. The experimental setup operates at $6.78 \mathrm{MHz}$, and it can transfer $20 \mathrm{~W}$ with $80 \%$ efficiency. A capacitive Class- $\mathrm{E}^{2} \mathrm{DC}$-DC converter able to transfer $1.7 \mathrm{~W}$ over a distance of $5 \mathrm{~mm}$ with $75 \%$ efficiency operating at $1 \mathrm{MHz}$ is presented in [25]. In [26], a Class-E power amplifier for capacitively coupled for biomedical implants is presented. The system can transfer $5 \mathrm{~W}$ with $96.34 \%$ efficiency operating at $13.56 \mathrm{MHz}$. Being designed for biomedical applications, the rated output power is limited to ensure safe operations. In [27], a Class-E capacitive power transfer with a full-wave rectifier able to transfer $3 \mathrm{~W}$ with $85 \%$ efficiency operating at $6.78 \mathrm{MHz}$ is presented. In [28], the ZVS operation of a capacitive Class-E inverter is extended by adding or removing capacitances to operate in resonance. The experimental setup operates at $2 \mathrm{MHz}$ and can transfer $360 \mathrm{~mW}$. In [29], an LC capacitive Class-E inverter able to transfer $10 \mathrm{~W}$ operating at $1 \mathrm{MHz}$ with $93.4 \%$ conversion efficiency is presented. Finally, in [30], a capacitive Class-E inverter able to transfer $9.45 \mathrm{~W}$ operating at $1 \mathrm{MHz}$ with $98.44 \%$ efficiency is presented.

A Class-E inverter circuit is sensitive to the parameters due to the CWPT operations, e.g., at a given input voltage, the power flow strongly depends on the capacitive coupling, that is, to the distance of the plates. Some researchers have been led out to maintain the ZVS operation by a proper control methodology such as in [28], where suitable capacitors have been added to achieve ZVS despite the variations of the capacitive coupling or load conditions. To preserve ZVS operation without a control methodology approach in the case of the distance variation between the two plates of CWPT, an impedance matching circuit in the Class-E converter is needed; in [31], the variation of capacitive coupling is analyzed versus the distance of the plates, this paper investigation is derived at a constant resistive load. ZVS also depends on the load when the distance among the capacitive plates is constant [25].

This paper investigates the influence of the capacitor coupling at a constant load to determine the conditions that allow the soft-switching operations to be maintained. The analysis is based on the analytical model developed in [32,33]; several simulations have been carried out to evaluate the effects of capacitive coupling on the ZVS operative conditions. A laboratory prototype has been built and tested to validate the analysis and simulation results. The experimental Class-E inverter with single silicon super junction MOSFET features a $100 \mathrm{kHz}$ switching frequency, a $V_{\text {in }}=21 \mathrm{~V}$ input voltage, and an output power rate up to $P_{o}=83.5 \mathrm{~W}$ with maximum efficiency of $92.5 \%$. Furthermore, the analysis of the capacitive coupling impact in CWPT on the ZVS operation allows optimizing the converter design giving some correct guidelines for an effective project of a CWPT system with a Class-E converter.

The paper in brief is organized as follows. In Section 2, the analysis of the coupling capacitance in CWPT applications is introduced to clarify the issues focused in the paper. In Section 3 the Class-E converter is analyzed, and an optimum design procedure is carried out. In Section 4, the variation of the coupling capacitance and its impact on ZVS operation are investigated. In Section 5, simulations and experimental results are presented to show the ZVS and ZDS versus different coupling capacitance conditions at a constant load.

Finally, the processed data are discussed and linked to derive appropriate design constraints for the Class E converter in CWPT applications.

\section{LC Compensated Capacitive Wireless Power Transfer System}

The four-plate parallel structure, shown in Figure 2a, represents the most common solution to create air-coupled capacitors [9]. As shown in [34] and Figure 2a, plates $P_{1}$ and $P_{3}$ represent the primary side plates, while $P_{2}$ and $P_{4}$ are the secondary side plates. In 
general, the coupling between the plates $P_{i}$ and $P_{j}$ is modeled by a capacitance $C_{i j}$. The couplings $C_{12}$ and $C_{34}$ are known as main capacitances, while $C_{14}, C_{23}, C_{24}$, and $C_{13}$ are called cross-coupling capacitances. Adopting the parallel structures shown in Figure 2a and assuming that the plates $P_{1}$ and $P_{2}$ are distant enough from $P_{3}$ and $P_{4}$ the cross-coupling capacitances can be neglected, making the analysis of the circuit easier. The analysis proposed in this paper is valid for any four-plate architecture system; therefore, even the cross-coupling capacitances are taken into account. By applying the Kirchhoff voltage law $(\mathrm{KVL})$ and the Kirchhoff current law (KCL) to Figure 2a, it is possible to reconfigure the six-capacitance matrix into the equivalent $\pi$-topology circuit shown in Figure $2 b$, where

$$
\begin{gathered}
C_{M}=\frac{C_{24} C_{13}-C_{14} C_{23}}{C_{13}+C_{14}+C_{23}+C_{24}} \\
C_{A}=C_{12}+\frac{\left(C_{13}+C_{14}\right)\left(C_{23}+C_{24}\right)}{C_{13}+C_{14}+C_{23}+C_{24}}-C_{M} \\
C_{B}=C_{34}+\frac{\left(C_{13}+C_{23}\right)\left(C_{14}+C_{24}\right)}{C_{13}+C_{14}+C_{23}+C_{24}}-C_{M}
\end{gathered}
$$

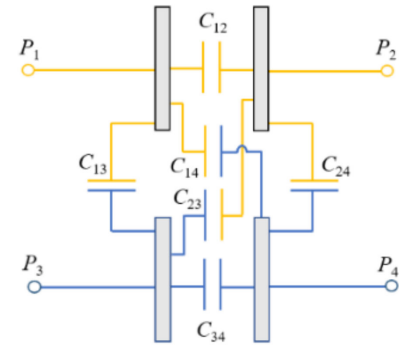

(a)

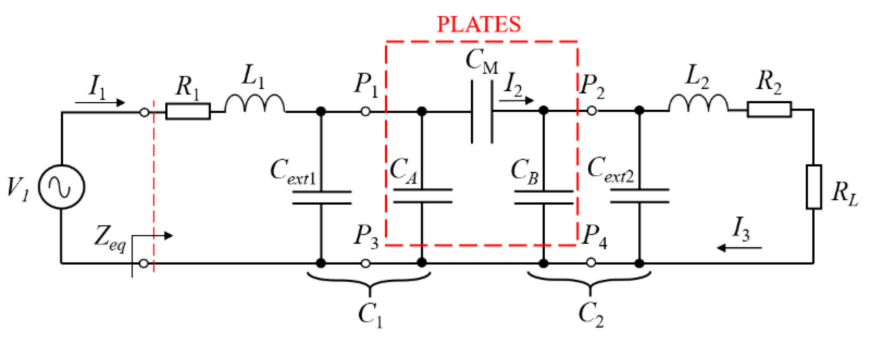

(b)

Figure 2. Parallel four plates structure. (a) Coupling capacitances. (b) Equivalent electric circuit of CWPT.

The plates being coupled through the air, the values of these capacitances usually are of few $\mathrm{pF}$; thus, a high operating frequency must be used. To transfer the desired power to the load at any frequency, two external capacitances $C_{1}$ and $C_{2}$ are connected in parallel with $C_{A}$ and $C_{B}$ and must be designed to resonate with inductances $L_{1}$ and $L_{2}$ at an angular frequency $\omega_{0}$. The insertion of these two external capacitances produces two equivalent capacitances $C_{1}=C_{\text {ext } 1}+C_{A}$ and $C_{2}=C_{\text {ext } 2}+C_{B}$, as shown in Figure $2 \mathrm{~b}$. To reduce the reactive power due to the low coupling between metal plates and increase the active output power, two external inductances $L_{1}$ and $L_{2}$ must be designed; to resonate with the capacitances $C_{1}$ and $C_{2}$, their values are derived as follows

$$
\begin{gathered}
L_{1}=\frac{1}{\omega_{0}^{2} C_{1}} \\
L_{2}=\frac{1}{1-k_{c}} \frac{1}{\omega_{0}^{2} C_{2}}
\end{gathered}
$$

where $k_{c}$ is the coupling factor, and it is expressed as

$$
k_{c}=\frac{C_{M}}{\sqrt{C_{1} C_{2}}}
$$

Being $C_{1} \gg C_{M}$ and $C_{2} \gg C_{M}$, the coupling coefficient $k_{c} \cong 0$. 


\subsection{Equivalent Impedance}

The knowledge of the equivalent impedance of the CWPT is crucial to achieve ZVS. Usually, the external capacitances are higher than the cross-capacitance, thus $C_{1}=C_{\text {ext } 1}+C_{A} \cong C_{\text {ext } 1}$ and $C_{2}=C_{\text {ext } 2}+C_{B} \cong C_{\text {ext } 2}$. The geometry of the plates is symmetrical resulting in $R_{1}=R_{2}=R, L_{1}=L_{2}=L$ and $C_{1}=C_{2}=C$; the equivalent impedance is

$$
Z_{e q}=\frac{1+\omega^{2}\left[\alpha\left(R \beta-\omega^{2} L^{2}\right)-2 L C\right]+j \omega\left[(R+\beta)\left(C+\alpha \omega^{2} L\right)\right]}{\alpha \beta \omega^{2}+j \omega\left(C-\alpha \omega^{2} L\right)}
$$

where $\alpha=C_{M}^{2}-C_{1} C_{2}$ and $\beta=R+R_{L}$. The impedance $Z_{e q}=R_{e q}+\mathrm{j} X_{e q}$ real and imaginary parts are

$$
\begin{aligned}
& R_{e q}=\frac{\alpha \beta\left\{1+\omega^{2}\left[\alpha\left(R \beta-\omega^{2} L^{2}\right)-2 L C\right]\right\}+\left[(R+\beta)\left(C+\omega^{2} L \alpha\right)^{2}\right]}{\omega^{2} \alpha^{2} \beta^{2}+\left(C+\omega^{2} L \alpha\right)^{2}} \\
& X_{e q}=\frac{\left(C+\omega^{2} L \alpha\right)\left\{\alpha \omega^{2}(R+\beta)-1-\omega^{2}\left[\alpha\left(R \beta-\omega^{2} L^{2}\right)-2 L C\right]\right\}}{\omega\left[\omega^{2} \alpha^{2} \beta^{2}+\left(C+\omega^{2} L \alpha\right)^{2}\right]}
\end{aligned}
$$

The sign of the reactive part $X_{e q}$ changes depending on the value of the coupling capacitance $C_{M}$. The value of $C_{M}$ resulting in $X_{e q}=0 \Omega$ is

$$
C_{0}=\sqrt{C^{2}+\frac{1-2 \omega^{2} L C}{\omega^{2}\left(\beta^{2}+\omega^{2} L^{2}\right)}}
$$

If $C_{M}<C_{0}$, the reactance $X_{e q}>0 \Omega$ and the equivalent impedance is resistiveinductive with

$$
L_{e q}=\frac{X_{e q}}{\omega_{O}}=\frac{\left(C+\alpha \omega^{2} L\right)\left\{\alpha \omega^{2}(R+\beta)-1-\omega^{2}\left[\alpha\left(R \beta-\omega^{2} L^{2}\right)-2 L C\right]\right\}}{\omega^{2}\left[\alpha^{2} \beta^{2} \omega^{2}+\left(C+\alpha \omega^{2} L\right)^{2}\right]}
$$

On the other hand, $C_{M}>C_{0}$ results in $X_{e q}<0 \Omega$ and the equivalent impedance is resistive-capacitive with

$$
C_{e q}=-\frac{1}{\omega_{O} X_{e q}}=-\frac{\left(C+\alpha \omega^{2} L\right)^{2}+\alpha^{2} \beta^{2} \omega^{2}}{\left(C+\alpha \omega^{2} L\right)\left\{\alpha \omega^{2}(R+\beta)-1-\omega^{2}\left[\alpha\left(R \beta-\omega^{2} L^{2}\right)-2 L C\right]\right\}}
$$

The blue trace in Figure 3 a represents the ratio between the equivalent resistance $R_{e q}$ and the load resistance $R_{L}$, while the red trace represents the reactance $X_{e q}$ for different values of capacitive coupling $C_{M}$. In Figure $3 \mathrm{~b}$, the ratio is between the equivalent resistance $R_{e q}$ and the load resistance $R_{L}$, while the red trace represents the reactance $X_{e q}$ for different values of load resistance $R_{L}$. In Figure $3 \mathrm{c}$, the variation of $R_{e q} / R$ under both coupling and load resistance variation is shown, while in Figure $3 d$, the 3D plot of the reactive part $X_{e q}$ for different coupling and load resistance is shown. 


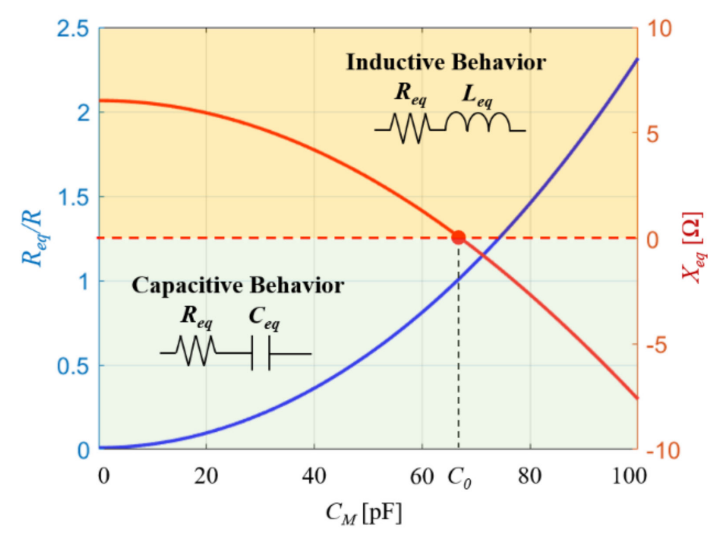

(a)

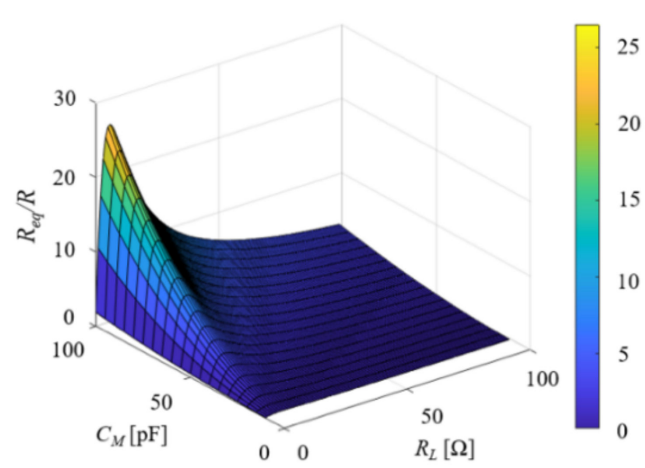

(c)

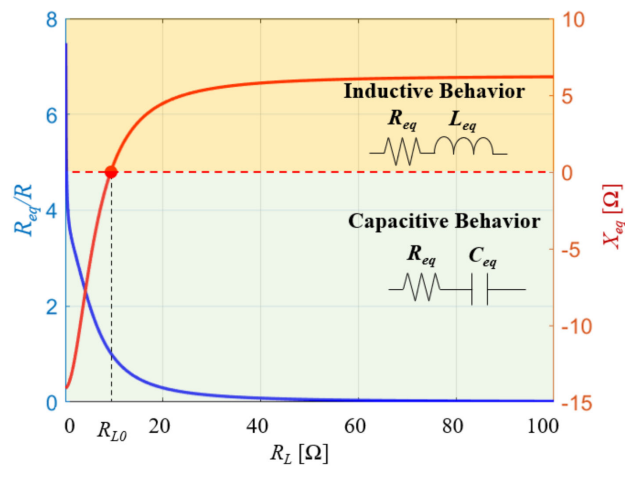

(b)

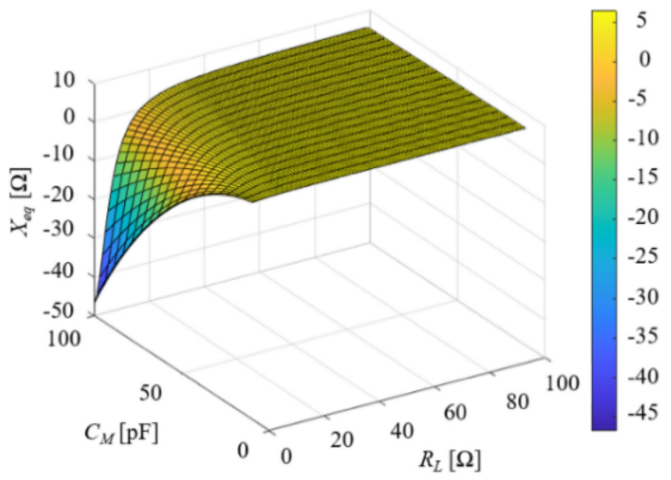

(d)

Figure 3. Equivalent impedance under capacitive coupling and load resistance variations. (a) Real and imaginary equivalent impedance part at fixed load resistance $R_{L}=10 \Omega$ and different coupling capacitance $C_{M}$. (b) Real and imaginary equivalent impedance part at fixed load resistance $C_{M}=32 \mathrm{pF}$. (c) The real part of the equivalent impedance. (d) The imaginary part of the equivalent impedance.

\subsection{Efficiency and Output Power}

The efficiency is calculated as

$$
\eta=\frac{P_{o}}{P_{o}+P_{\text {in }}}=\frac{R_{L}}{R_{L}+R_{2}+R_{1}\left|\frac{I_{1}}{I_{3}}\right|^{2}}
$$

where the ratio between the input and output currents is expressed by applying the KVL and KCL to the circuit of Figure $2 b$ as

$$
\frac{I_{1}}{I_{3}}=\frac{C_{M}}{C} \frac{\beta\left(R_{e q}-R\right)+\omega L X_{e q}+j\left[\omega L\left(R_{e q}-R\right)-\beta X_{e q}\right]}{\left(R_{e q}-R\right)^{2}+X_{e q}^{2}}
$$

Assuming that the CWPT operates at the resonance, (14) simplifies as

$$
\left|\frac{I_{1}}{I_{3}}\right|^{2}=\frac{C_{M}^{2}}{C^{2}} \frac{\beta^{2}+\omega^{2} L^{2}}{\left(R_{e q}-R\right)^{2}+X_{e q}^{2}}
$$

Thus, the transmission efficiency is

$$
\eta=\frac{R_{L}}{\beta C^{2}\left[\left(R_{e q}-R\right)^{2}+X_{e q}^{2}\right]+R_{1} C_{M}^{2}\left(\beta^{2}+\omega^{2} L^{2}\right)}
$$


and the output current is expressed as

$$
I_{3}=-\frac{C_{M}}{C_{M} R_{L}+j \omega \beta R\left(C^{2}-C_{M}^{2}\right)}
$$

leading to an output power given by

$$
P_{o}=-\frac{V_{i}^{2} C_{M}^{2} R_{L}}{\left(R_{L} C_{M}\right)^{2}+\left[\omega \beta R\left(C^{2}-C_{M}^{2}\right)\right]^{2}}
$$

\section{CWPT Class-E Inverter Circuit Analysis}

In this section, the integration of the CWPT system with the Class-E inverter is presented.

\subsection{Assumptions}

The analysis is derived according to the following assumptions.

- $\quad$ The duty cycle $D$ of the MOSFET is 0.5 ;

- The MOSFET turns ON and OFF instantly;

- The MOSFET ON-resistance is zero;

- The MOSFET output capacitance is linear and frequency invariant;

- The loaded quality factor $Q_{L}$ of the resonant network is high enough such that the currents through the transformer windings are sinusoidal (e.g., $Q_{L}>7$ );

- The choke inductance is large enough to neglect the input current ac component. The dc resistance of the choke inductor is ignored. The self-capacitance of the choke inductor is absorbed into the shunt capacitance of the MOSFET.

\subsection{Circuit Descriptions}

Figure 4a shows the Class-E DC-AC inverter for capacitive wireless power applications. Here, $V_{i}$ is the DC supply voltage source, $L_{f}$ is the choke inductor, $S$ is the switch implemented by using a power MOSFET, and $C_{\text {shunt }}$ is the voltage-shaping shunt capacitor across the switch. The power MOSFET output capacitance and the self-capacitance of the choke are included in the overall capacitance $C_{\text {shunt }}$ connected in parallel with the switch.

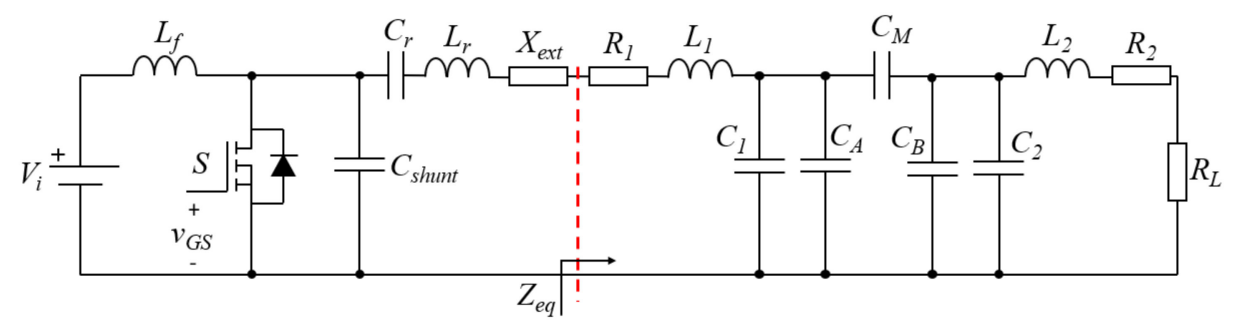

(a)

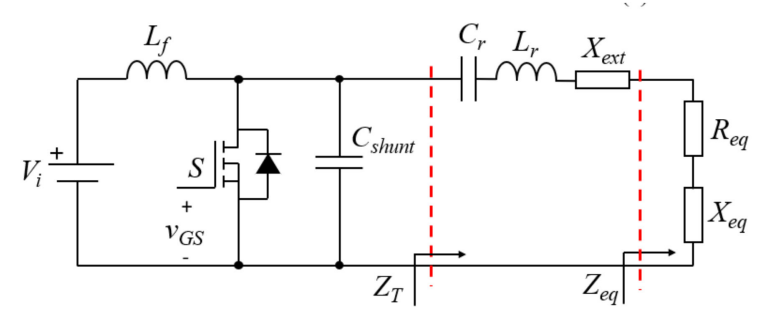

(b)

Figure 4. Circuit of capacitive wireless power transfer Class-E inverter. (a) Circuit topology. (b) Circuit topology with equivalent impedance. 
In some applications, it is preferable to work at not excessively high frequencies, especially when the transferred power is high. Therefore, to integrate the CWPT into the Class-E inverter topology, it is necessary to add the capacitances $C_{1}$ and $C_{2}$ and the inductances $L_{1}$ and $L_{2}$, as shown in Figure 4a. The circuit can be represented in the basic topology of Figure $4 \mathrm{~b}$ introducing the equivalent impedance of CWPT $Z_{\text {eq }}$. Then, the components $C_{r}$ and $L_{r}$, representing the resonant tank, can be properly tuned to achieve inductive load for soft-switching operation. The typical voltage and current waveforms of the circuit operating at ZVS/ZDS conditions are shown in Figure 5.

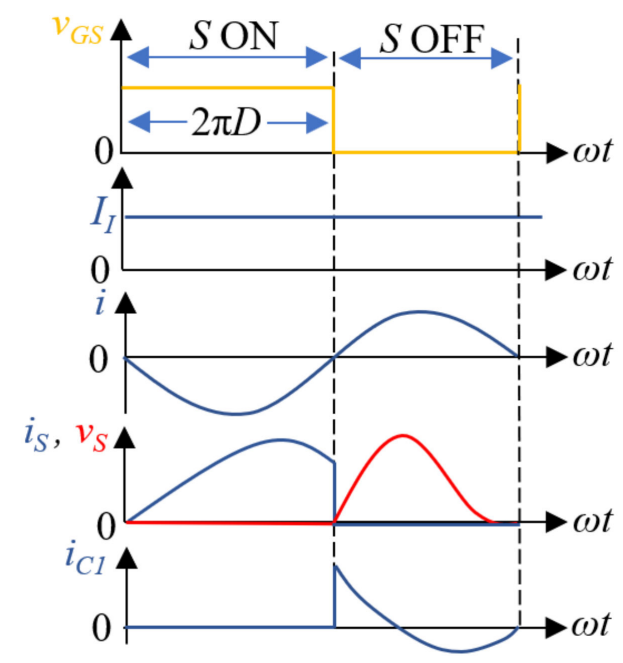

Figure 5. Waveforms in Class-E zero-voltage-switching inverter for optimum operation.

\subsection{Optimum Design Procedure}

Figure $4 \mathrm{~b}$ shows the DC-AC Inverter where the CWPT system is replaced by its equivalent impedance $Z_{e q}=R_{e q}+\mathrm{j} X_{e q}$. As discussed in the previous section, depending on the value of $C_{M}$, the equivalent reactance results to be either inductive or capacitive, as shown in Figure 3b. Let us assume that the system is working at the switching frequency $f=\omega /(2 \pi)$.

Depending on the application, an optimal value of coupling $C_{M}{ }^{\text {opt }}$ must be defined.

To reduce the current circulation, the reactive part of the equivalent impedance $X_{e q}$ must be canceled by adding an external reactance $X_{\text {ext }}$ in series, leading to

$$
X_{e x t}=-X_{e q}
$$

In this way, when the system operates at $C_{M}=C_{M}$ opt, the equivalent impedance of the CWPT system is purely resistive $Z_{e q}=R_{e q}$. The external inductance, which must be series connected to the LC resonant tank when $X_{\text {eq }}<0 \Omega$ to satisfy (19), is

$$
L_{e x t}=-\frac{1}{\omega X_{e q}}=\frac{1}{\omega^{2} C_{e q}}
$$

When $X_{e q}>0 \Omega$, the external capacitance series-connected with the LC resonant tank to satisfy (19) is given by

$$
C_{e x t}=\frac{1}{\omega X_{e q}}=\frac{1}{\omega^{2} L_{e q}}
$$

Assuming that the load resistance $R_{L}$, the operating frequency $f_{0}=\omega_{0} /(2 \pi)$, and the output power $P_{o}$ values are known as design specifications, the expressions for the components needed to reach the ZVS and ZDS condition at $C_{M}=C_{M}^{\text {opt }}$ are given by [35]

$$
V_{i}=\sqrt{\frac{\pi^{2}+4}{8} P_{o} R_{e q}}
$$




$$
\begin{gathered}
C_{\text {shunt }}=\frac{8}{\pi\left(\pi^{2}+4\right)} \frac{1}{\omega C_{1} R_{e q}} \\
L_{r}=\frac{Q_{L} R_{e q}}{\omega} \\
C_{r}=\frac{1}{\omega R_{e q}\left(Q_{L}-\frac{\pi\left(\pi^{2}-4\right)}{16}\right)}
\end{gathered}
$$

Regarding the choke inductor, it can be calculated as [36]

$$
L_{f}=\frac{14 \pi R_{e q}}{\omega}
$$

If the position of plates is not in the optimal position, the coupling is different from the nominal value $C_{M}{ }^{o p t}$, and therefore (19) is not satisfied. An in-depth analysis of the Class-E inverter under misalignment between plates is derived in Section 4.

\subsection{Design Example}

In this case of study, the considered power inverter has a nominal output power $P_{O}=100 \mathrm{~W}$, the load resistance is $R_{L}=10 \Omega$, the operating frequency is $f_{0}=100 \mathrm{kHz}$, and the quality factor is selected to be $Q_{L}=10$. The parasitic resistances are assumed to be $R_{1}=R_{2}=0.1 \Omega$.

The coupling capacitance is $C_{M}=64 \mathrm{pF}$. It is assumed that $C_{A}$ and $C_{B}$ are much lower than the external capacitances $C_{1}$ and $C_{2}$. These capacitances are fixed as $C_{1}=C_{2}=3 \mathrm{nF}$. From (6), the coupling factor is $k_{c}=0.023$. Thus, the primary and secondary inductances are

$$
L_{1}=L_{2}=\frac{1}{1-k_{c}} \frac{1}{\omega_{0}^{2} \mathrm{C}}=844 \mu \mathrm{H}
$$

From (8)-(20), the equivalent impedance is $Z_{e q}=R_{e q}+\mathrm{j} X_{e q}=3.2-\mathrm{j} 0.0411, X_{e q}<0$, according to (11)-(21), so

$$
\begin{gathered}
C_{e q}=\frac{1}{\omega X_{e q}}=38.7 \mu \mathrm{F} \\
L_{e x t}=\frac{1}{\omega^{2} C_{e q}}=65.4 \mathrm{nH}
\end{gathered}
$$

Finally, by using (22)-(26), the shunt capacitance, the resonant inductance, the resonant capacitor, and the choke inductance are calculated as $C_{\text {shunt }}=91 \mathrm{nF} L_{r}=51 \mu \mathrm{H}, C_{r}=56 \mathrm{nF}$, and $L_{f}=200 \mu \mathrm{H}$, respectively.

The proposed design procedure is represented as a flowchart in Figure 6. Starting from the four plates capacitive wireless power transfer structure, the equivalent $\pi$ electric circuit can be extrapolated. Defining the system characteristics, such as the operating frequency, the output power, and the load resistance, the equivalent impedance $Z_{e q}$ can be calculated. To cancel the reactive part $X_{e q}$, a capacitor $C_{e x t}$ can be added if $X_{e q}>0$. 


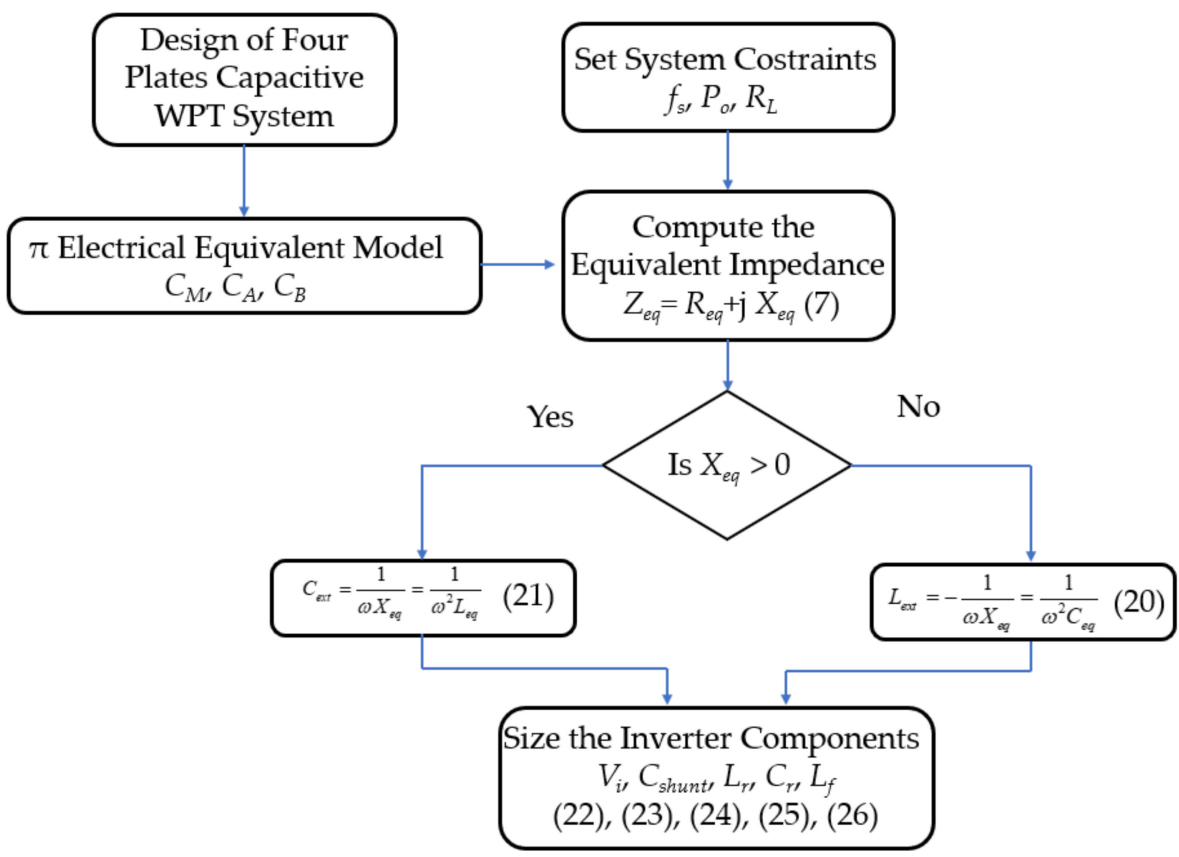

Figure 6. Design procedure flowchart representation.

\section{Class-E Inverter Behavior at Any Coupling Coefficient}

\subsection{Analytical Model}

In this section, the analytical expressions of current and voltage waveforms across the components are derived. According to Figure 4, an equivalent impedance $Z_{T}=R_{T}+\mathrm{j} X_{T}$ can be defined; its phase is

$$
\psi=\arctan \left(\frac{R_{T}}{X_{T}}\right)
$$

The current through the series-resonant circuit is sinusoidal and given by

$$
i=I_{m} \sin (\omega t+\varphi)
$$

where $I_{m}$ is the amplitude, and $\varphi$ is the initial phase. The vector relationship between the angle $\psi$ and $\varphi$ is shown in Figure 7. If $X_{T}>0 \Omega$, the voltage across the equivalent inductance $V_{L T}$ leads by $90^{\circ}$ the voltage across the equivalent resistance $V_{R T}$, as shown in Figure 7a; while if $X_{T}<0 \Omega$, voltage $V_{R T}$ leads by $90^{\circ}$ voltage $V_{C T}$, as shown in Figure $7 \mathrm{~b}$.

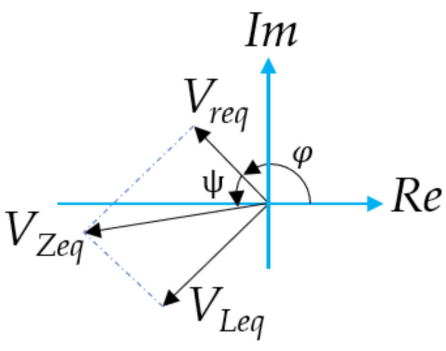

(a)

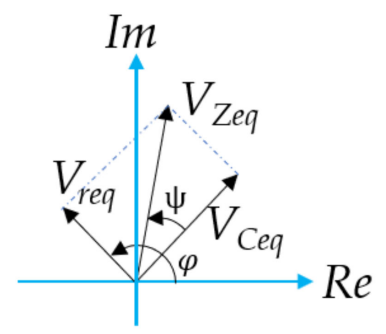

(b)

Figure 7. Vector representation of the relationship between $\varphi$ and $\psi$ angles. (a) Resistive-inductive equivalent impedance. (b) Resistive-capacitive equivalent impedance. 
If the impedance is resistive-inductive, the first harmonic of the voltage $v^{1}{ }_{\text {shunt }}$ applied to $Z_{T}$ can be split into the voltage across the equivalent resistance $R_{T}$ and that across the equivalent reactance $X_{T}$.

$$
v_{\text {shunt }}^{1}(\omega t)=v_{R t}(t)+v_{L t}(t)=V_{R t} \sin (\omega t+\varphi)+V_{L t} \cos (\omega t+\varphi)
$$

Using (31), the relationship between the angles $\psi$ and $\varphi$, at a fixed duty cycle is derived as

$$
\tan (\psi)=\frac{\pi^{2}+2 \cos (\psi) \cos (2 \pi D+\psi)+\cos (2(\pi D+\psi))-1}{4 \sin (\pi D+\psi) \cos (\pi D+\psi)}
$$

This relationship is also shown in Figure 8, for three different values of the duty cycle.

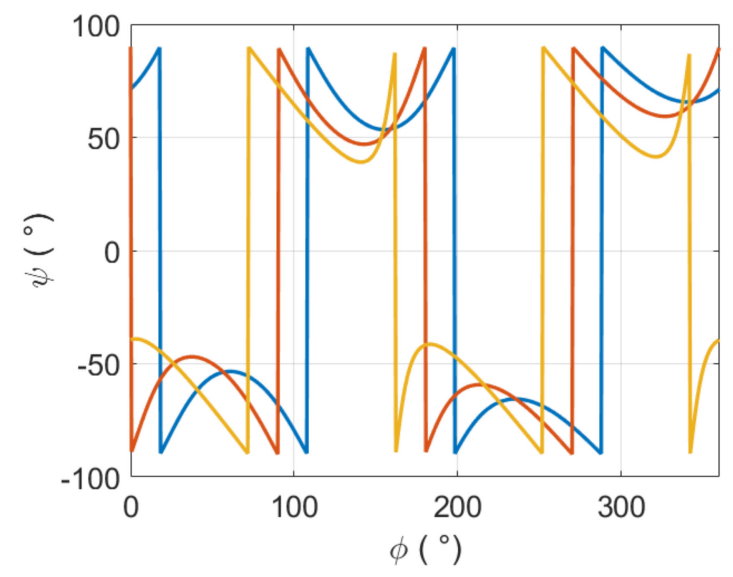

Figure 8. Relationship between $\varphi$ and $\psi$ angles.

The drain to source voltage across the MOSFET is

$$
v_{\mathcal{S}}(\omega t)=\frac{1}{C_{1}} \int_{2 \pi D}^{\omega t} i_{C 1} d \omega t= \begin{cases}0 & 0<\omega t<2 \pi D \\ \frac{1}{\omega C_{1}}\left\{I_{I}(\omega t-2 \pi D)+I_{m}[\cos (\omega t+\varphi)-\cos (2 \pi D+\varphi)]\right\} & 2 \pi D<\omega t<2 \pi\end{cases}
$$

If the choke inductance $L_{f}$ is big enough to assume the input current $I_{I}$ to be constant, the input voltage $V_{I}$ can be calculated as the average value of the $v_{S}$

$$
\begin{aligned}
& V_{i}=\frac{1}{2 \pi} \int_{2 \pi D}^{2 \pi} v_{s} d(\omega t)=\frac{1}{2 \pi} \int_{2 \pi D}^{2 \pi} \frac{1}{\omega C_{1}}\left\{I_{i}(\omega t-2 \pi D)+I_{m}[\cos (\omega t+\varphi)-\cos (2 \pi D+\varphi)]\right\} d(\omega t)= \\
& =\frac{1}{2 \pi \omega C_{1}}\left\{2 \pi I_{i}(1-D)^{2}+I_{m}\{\sin (\varphi)[1-\cos (2 \pi D)]-\sin (2 \pi D) \cos (\varphi)-2 \pi(1-D) \cos (2 \pi D+\varphi)\}\right\}
\end{aligned}
$$

Under the assumptions used for this analysis, the power losses for the circuit can be neglected. This means that $P_{o}=V_{o} I_{o}$ and $P_{i}=V_{i} I_{i}$. Thus, the amplitude of the current through the resonant tank can be expressed as

$$
I_{m}=\frac{2 \pi \omega V_{i}-2 \pi^{2} I_{i}(1-D)^{2}}{\sin (\varphi)[1-\cos (2 \pi D)]-\sin (2 \pi D) \cos (\varphi)-2 \pi(1-D) \cos (2 \pi D+\varphi)}
$$

\subsection{Voltage and Current Waveforms}

The equations shown in the previous section allow the study of the system behavior under capacitive coupling changes. Using (34) and (36), the voltage and the current through the MOSFET for three different values of coupling capacitance $C_{M}$ were calculated. The waveforms computed using the previous equations using the nominal values summarized in Table 1 are shown in Figure 9. 
Table 1. Component values for the designed system.

\begin{tabular}{cc}
\hline Parameter & Calculated \\
\hline$C_{\text {opt }}^{M_{i}}$ & $32 \mathrm{pF}$ \\
$V_{i}$ & $23.6 \mathrm{~V}$ \\
$L_{f}$ & $200 \mu \mathrm{H}$ \\
$C_{\text {shunt }}$ & $91 \mathrm{nF}$ \\
$L_{r}$ & $51 \mathrm{nH}$ \\
$C_{r}$ & $56 \mathrm{nF}$ \\
$L_{1}$ & $844 \mu \mathrm{H}$ \\
$C_{1}$ & $3 \mathrm{nF}$ \\
$L_{2}$ & $844 \mu \mathrm{H}$ \\
$C_{2}$ & $3 \mathrm{nF}$ \\
$R_{L}$ & $10 \Omega$ \\
\hline
\end{tabular}

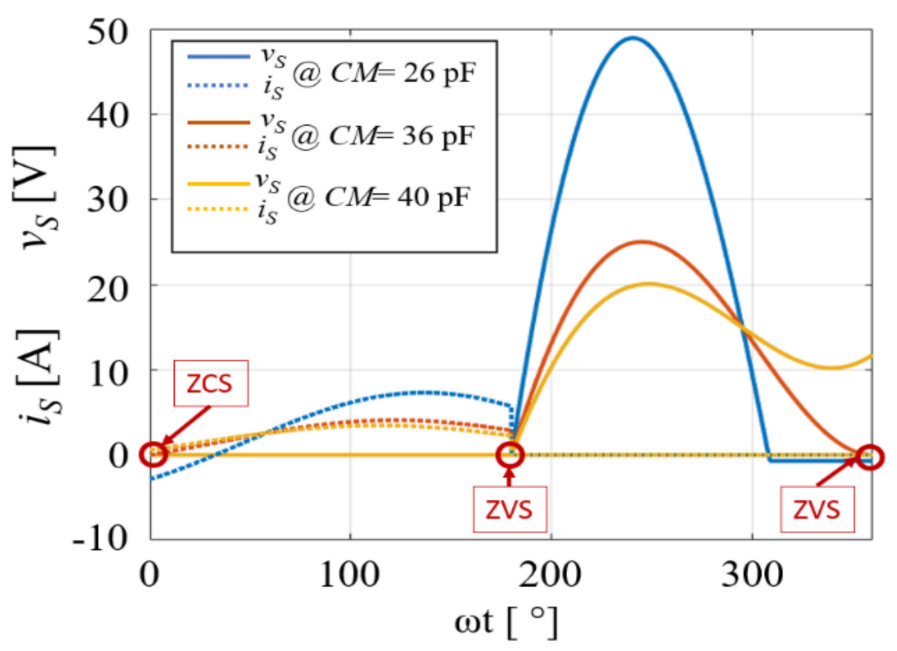

Figure 9. Voltage and current waveforms through the MOSFET for three different values of coupling capacitance $C_{M}$.

The dotted lines in Figure 9 represent the current through the MOSFET $i_{s}$, while the continuous line is the drain to source voltage $v_{s}$. Note that the ZVS/ZDS condition is achieved only for the optimum value of coupling capacitance $C_{M}{ }^{\text {opt }}=32 \mathrm{pF}$. When the plates are strayed leading to a lower coupling capacitance $C_{M}<C_{M}$ opt , the ZVS condition is still achieved, as shown for $C_{M}=25 \mathrm{pF}$. When $C_{M}=C_{M}$ opt , at $\omega t=0$ both ZCS and ZVS are reached, being both the current and the voltage across the MOSFET zero, while, when $\omega t=180^{\circ}$, only ZVS is achieved, being the current different from zero. When the plates come closer with respect to the optimum position $C_{M}>C_{M}$ opt , the ZCS condition is not achieved at $\omega t=0$, while it is almost achieved $C_{M}<C_{M}$ opt .

\section{Simulation and Experimental Results}

To validate the analysis results obtained using the analytical equations, the circuit was implemented in LTSpice and validated experimentally.

\subsection{Simulations}

The results obtained by using the analytical model described in the previous section are here validated through simulations. The circuit is implemented in LTSpice as shown in Figure 10 with the values component values shown in Table 1 . To evaluate the effects of misalignment, three different values of coupling capacitance $C_{M}$ were studied. Figure 11a shows the current and voltage waveforms resulting at $C_{M}=25 \mathrm{pF}$. The power delivered to the load is reduced to $P_{o}=89 \mathrm{~W}$, and also the efficiency reduces to $\eta=0.91$. In Figure $11 \mathrm{~b}$, the case with $C_{M}=C_{M}{ }^{\text {opt }}=32 \mathrm{pF}$ is considered, both ZVS and ZDS are achieved, the 
output power is $P_{o}=92 \mathrm{~W}$, and the system efficiency is $\eta=0.95$. Finally, the circuit with $C_{M}=45 \mathrm{pF}$ is simulated, ZVS condition is not achieved, and the transmitted power increases to $P_{o}=95 \mathrm{~W}$, but the converter efficiency further decreases to $\eta=0.89$, as shown in Figure 11c. Note that at $C_{M}=25, \mathrm{pF}$ ZVS is still achieved, but the voltage stress across the MOSFET significantly increases if compared with the other couplings.

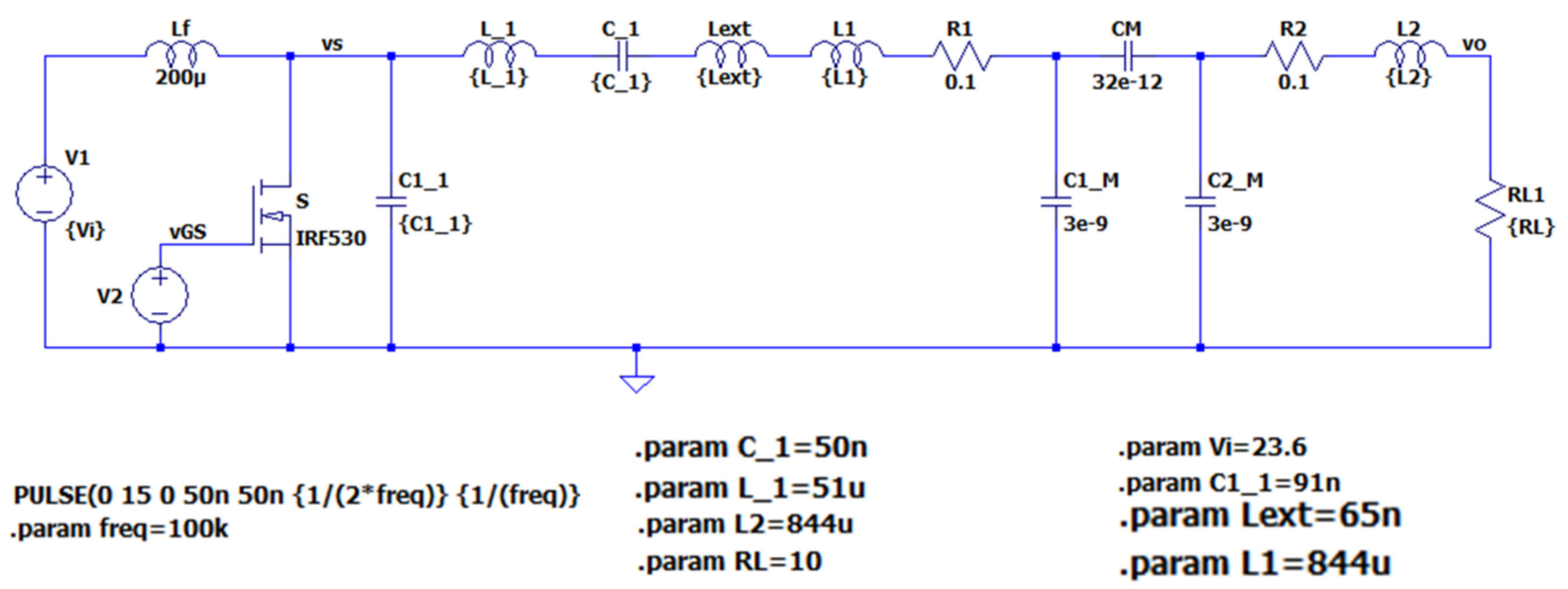

Figure 10. LTSpice circuit schematic.

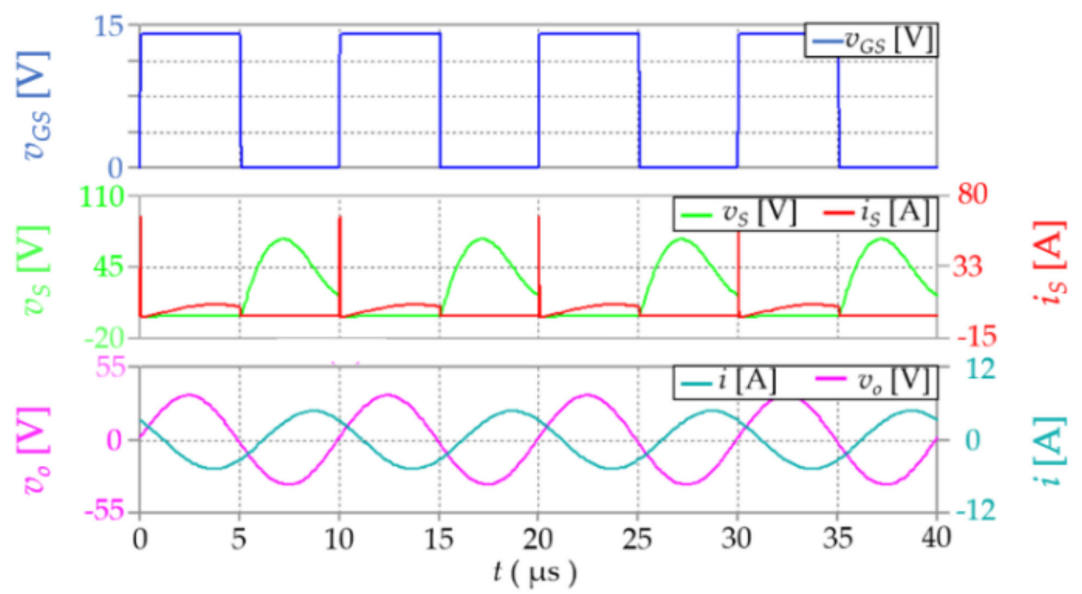

(a)

Figure 11. Cont. 


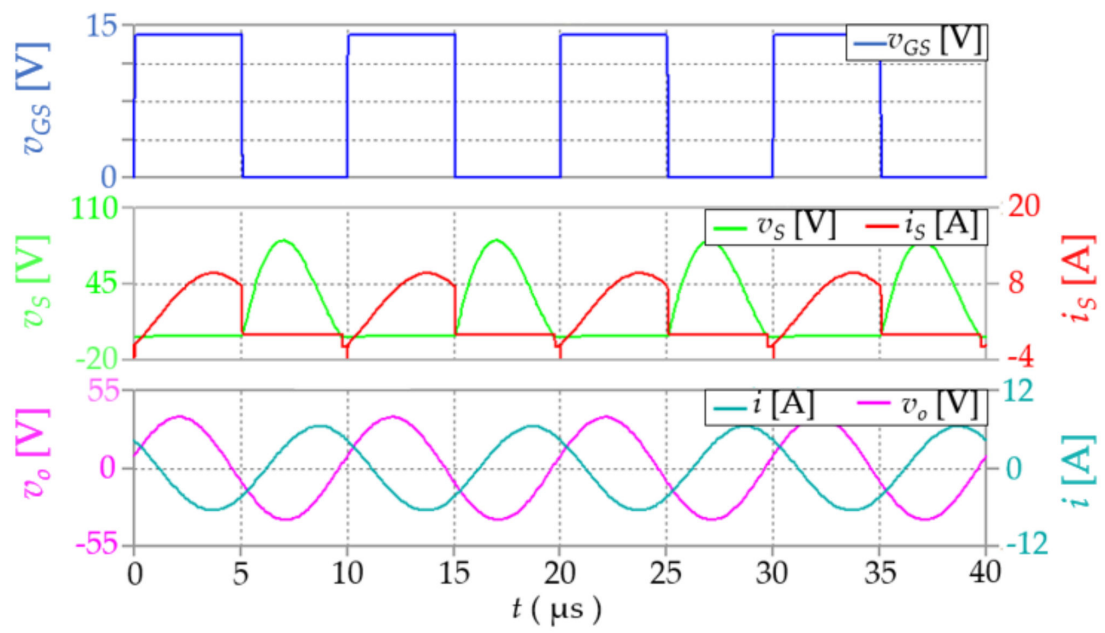

(b)

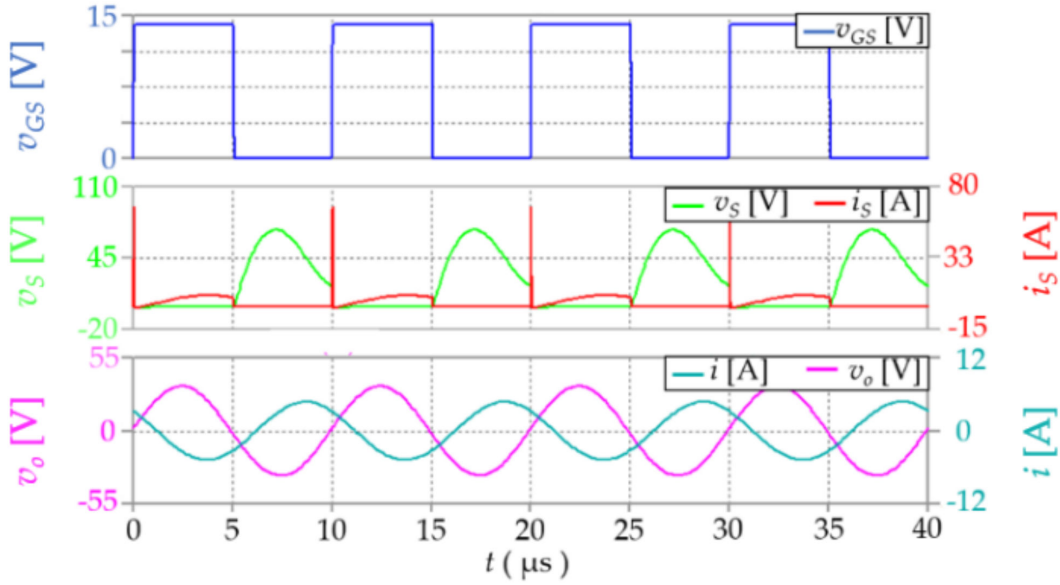

(c)

Figure 11. Simulated waveforms at several coupling capacitance $C_{M}$ values. (a) $25 \mathrm{pF}$. (b) $32 \mathrm{pF}$. (c) $45 \mathrm{pF}$.

\subsection{Experimental Results}

To validate the simulations, a power converter experimental circuit has been realized. A picture of the experimental setup is shown in Figure 12a. An enlargement of the PCB board is shown in Figure 12b, while the equivalent electric circuit is shown in Figure 12c. The four plates are steel made. The measured values and the component parasitic resistances are given in Table 2. The inductance was made by using AWG40 Litz wire to reduce the parasitic resistance at $f_{s}=100 \mathrm{kHz}$. A Silicon Super Junction MOSFET-R6020JNJ is used [37]. The main MOSFET parameters are reported in Table 3. 

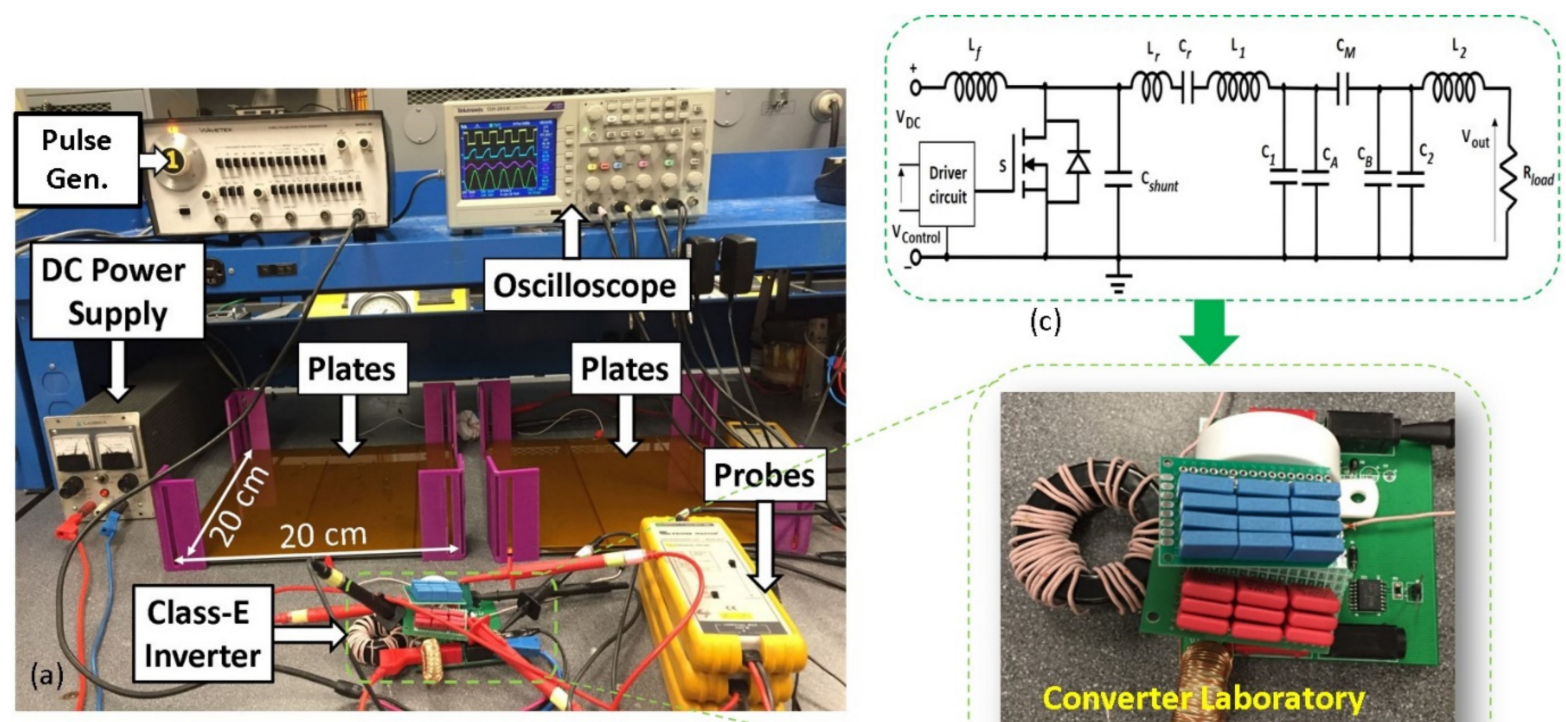

(c)

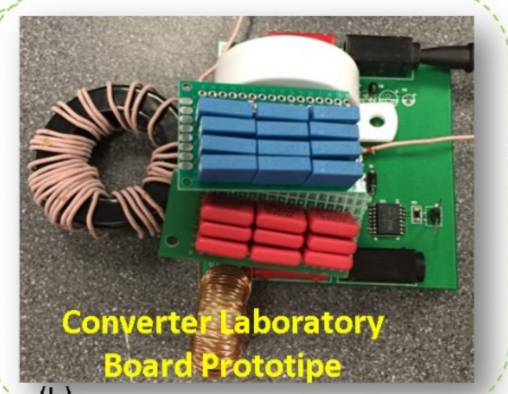

(b)

Figure 12. Experimental setup. (a) Board and instrumentations. (b) Experimental board. (c) Electrical schematic.

Table 2. Experimentally measured values of components and their parasitics.

\begin{tabular}{cc}
\hline Parameter & Measured \\
\hline$C^{M}{ }_{\text {opt }}$ & $32 \mathrm{pF}$ \\
$V_{i}$ & $23.6 \mathrm{~V}$ \\
$f_{S}$ & $100 \mathrm{kHz}$ \\
$L_{f}$ & $214.3 \mu \mathrm{H} / E S R_{L f}=26 \mathrm{~m} \Omega$ \\
$C_{\text {shunt }}$ & $90.2 \mathrm{nF} / E S R_{C s h u n t}=35 \mathrm{~m} \Omega$ \\
$L_{r}$ & $50.3 \mathrm{nH} / E S R_{L}=35 \mathrm{~m} \Omega$ \\
$C_{r}$ & $57.3 \mathrm{nF} / E S R_{C}=7 \mathrm{~m} \Omega$ \\
$L_{1}$ & $839.6 \mu \mathrm{H} / E S R_{L 1}=13 \mathrm{~m} \Omega$ \\
$C_{1}$ & $3.2 \mathrm{nF} / E S R_{C 1}=4 \mathrm{~m} \Omega$ \\
$L_{2}$ & $842.3 \mu \mathrm{H} / E S R_{L 2}=13 \mathrm{~m} \Omega$ \\
$R_{L}$ & $9.96 \Omega$ \\
\hline
\end{tabular}

Table 3. Main super junction MOSFET parameters.

\begin{tabular}{ccc}
\hline Parameter & Value & Conditions \\
\hline$V_{B R, D S S}$ & $600 \mathrm{~V}$ & $V_{G S}=0 \mathrm{~V}, I_{D}=1 \mathrm{~mA}$ \\
$R_{D S, O N}$ & $0.234 \Omega$ & $V_{G S}=15 \mathrm{~V}, I_{D}=10 \mathrm{~A}, T_{J}=25^{\circ} \mathrm{C}$ \\
$I_{D}$ & $20 \mathrm{~A}$ & $T_{a}=25^{\circ} \mathrm{C}$ \\
$C_{i s S}$ & $1500 \mathrm{pF}$ & $V_{G S}=0 \mathrm{~V}, V_{D S}=100 \mathrm{~V}, f=1 \mathrm{MHz}$ \\
$C_{\text {oss }}$ & $90 \mathrm{pF}$ & - \\
$C_{r S S}$ & $1.9 \mathrm{pF}$ & - \\
\hline
\end{tabular}

The experimental tests were performed under three different values of $C_{M}$. Figure 13a shows the waveforms at $C_{M}=25 \mathrm{pF}$. The amplitude of the $\mathrm{LC}$ resonant current is $I=8.9 \mathrm{~A}$, the output voltage is $V_{o}=39.8 \mathrm{~V}$, and the output power $P_{o}=80 \mathrm{~W}$ with a transmission efficiency $\eta=82.4 \%$. In Figure $13 \mathrm{~b}$, the measured waveforms at $C_{M}=C_{M}{ }^{\text {opt }}=32 \mathrm{pF}$ are shown. The waveforms of the current flowing into the LC resonant tank $i$ and that of the voltage across the load resistance $v_{0}$ are perfectly sinusoidal with amplitudes of $I=8.3 \mathrm{~A}$ and $V_{o}=28.9 \mathrm{~V}$, respectively. 


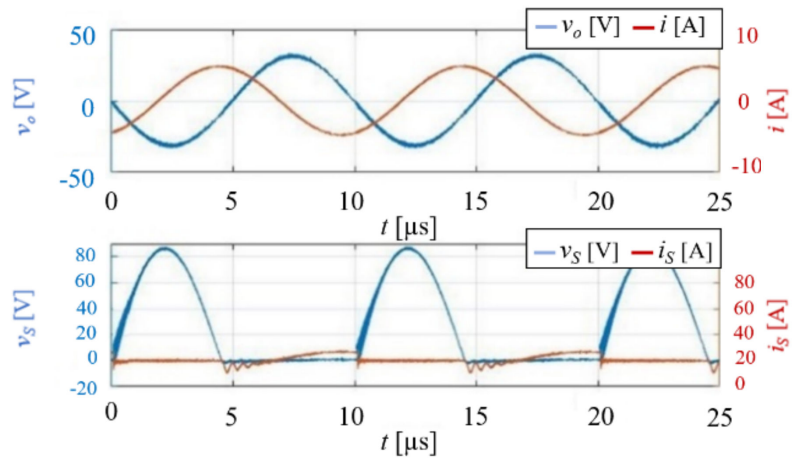

(a)
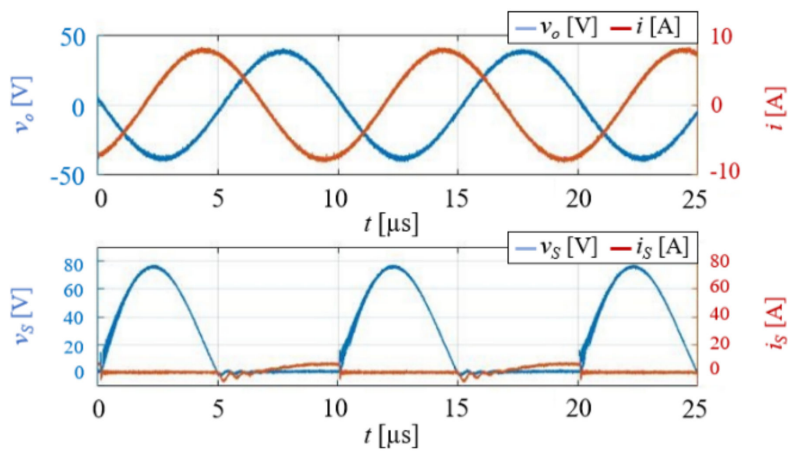

(b)

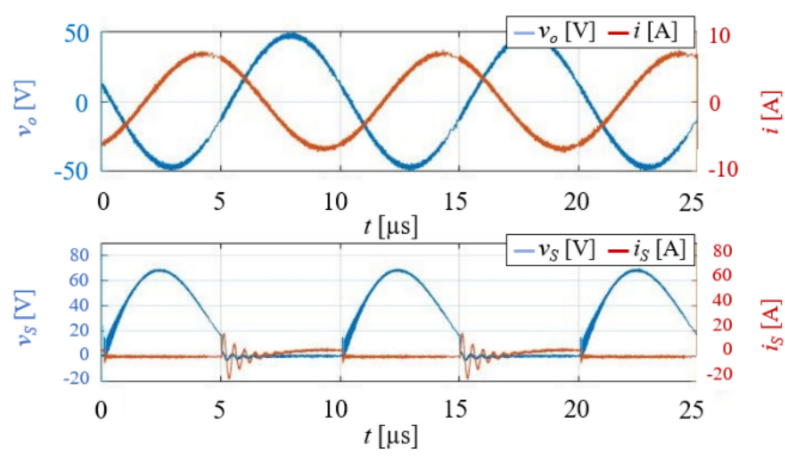

(c)

Figure 13. Experimental waveforms versus $C_{M}$ variations. (a) $25 \mathrm{pF}$. (b) $32 \mathrm{pF}$. (c) $45 \mathrm{pF}$.

The measured transmission efficiency is $\eta=92.5 \%$. Finally, in Figure 13c, the waveforms at $C_{M}=45 \mathrm{pF}$ are shown. The current flowing through the resonant tank stays approximately constant to $I=8.3 \mathrm{~A}$, but the voltage across the load is $V_{o}=47.8 \mathrm{~V}$, the transmitted power $P_{o}=90.6 \mathrm{~W}$, and a transmission efficiency $\eta=88.5 \%$. Concerning the achievement of the ZVS condition, it can be seen that for $C_{M}=25 \mathrm{pF}$, the ZVS condition is still achieved, but the voltage stress across the MOSFET is increased reaching a maximum voltage $V_{D S}{ }^{\max } \cong 90 \mathrm{~V}$.

Operating with $C_{M}=C_{M}{ }^{o p t}=32 \mathrm{pF}$, both the ZVS/ZDS conditions are achieved, while when the coupling increases as for $C_{M}=45 \mathrm{pF}$, the ZVS condition is not achieved anymore, leading to ringing and switching power losses.

The converter also results in a very low output voltage total harmonic distortion (THD) as shown in Table 4, where the DC component and the THD of the output voltage for the three different capacitive couplings are summarized. 
Table 4. Output voltage harmonic content.

\begin{tabular}{ccc}
\hline Capacitive Coupling & DC & THD \\
\hline $25 \mathrm{pF}$ & $493 \mu \mathrm{V}$ & $0.35 \%$ \\
$32 \mathrm{pF}$ & $238 \mu \mathrm{V}$ & $0.64 \%$ \\
$45 \mathrm{pF}$ & $238 \mu \mathrm{V}$ & $0.42 \%$ \\
\hline
\end{tabular}

Although the conversion efficiency is highly sensitive to coupling variation, the THD of the output voltage is also very low when the converter operates outside the optimum coupling.

An enlargement of the turn-on switching voltage and current waveforms for the three coupling cases is shown in Figure 14. The blue trace represents the voltage across the MOSFET $v_{S}$, while the red trace represents the current $i_{S}$. It can be seen that for both the cases, $C_{M}=25 \mathrm{pF}$ and $C_{M}=32 \mathrm{pF} \mathrm{ZVS}$ is achieved, while for $C_{M}=45 \mathrm{pF}$, the ZVS condition is not achieved, and a higher current oscillation occurs after the turn-on, thus leading to higher switching losses.

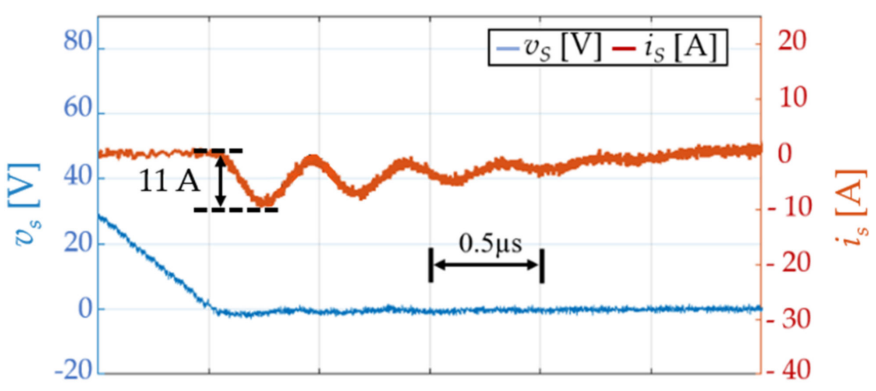

(a)

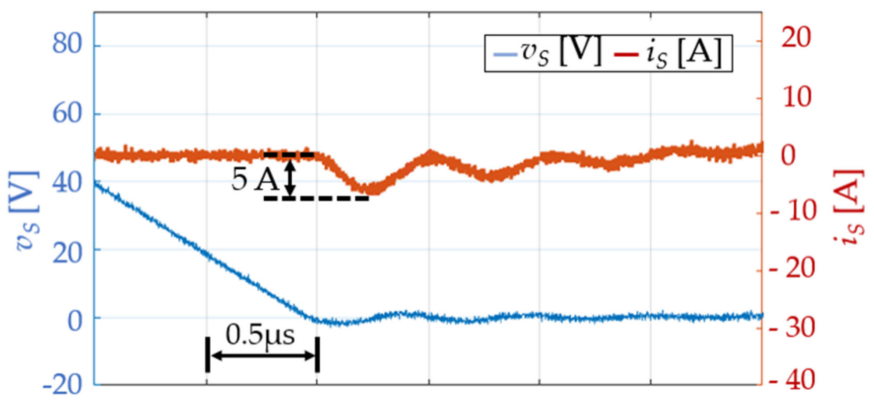

(b)

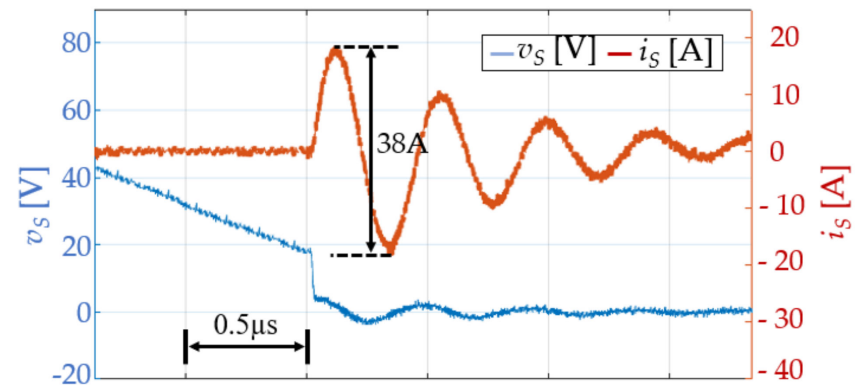

(c)

Figure 14. Drain-to-source voltage and current versus $C_{M}$ variation. (a) $25 \mathrm{pF}$. (b) $32 \mathrm{pF}$. (c) $45 \mathrm{pF}$. 
The experimental results confirm both the analysis and simulation results. Mutual capacitance $C_{M}$ is one of the key parameters to investigate to achieve the ZVS and ZDS operations. The same transient behavior obtained from analytical equations and simulations is highlighted. When plates are moved from the optimal position, ZVS is still reached, but the power is transferred to the load, and the efficiency decreases. On the other hand, when the plates are placed at a closer distance than that of the optimal position, the transferred power increases, but the ZVS is not achieved, leading to a lower transmission efficiency. The abovementioned behavior of the converter versus coupling capacitance $C_{M}$ is illustrated in Figure 15, where the experimentally measured output power and conversion efficiency are shown. The maximum DC-AC conversion efficiency occurs at the optimum coupling capacitance $C_{M}$ opt . This is due to the achievement of the ZVD/ZDS condition, which drastically reduces the MOSFET switching losses, while the conduction losses are mainly related to the switch current root mean square (RMS) $i_{\mathrm{s}, \mathrm{rms}}$ (Figure 9) and the $R_{\mathrm{DS}, \mathrm{ON}}$ of the chosen device [38,39]. Figure 15 also shows that the transferred power increases if the plate coupling increases.

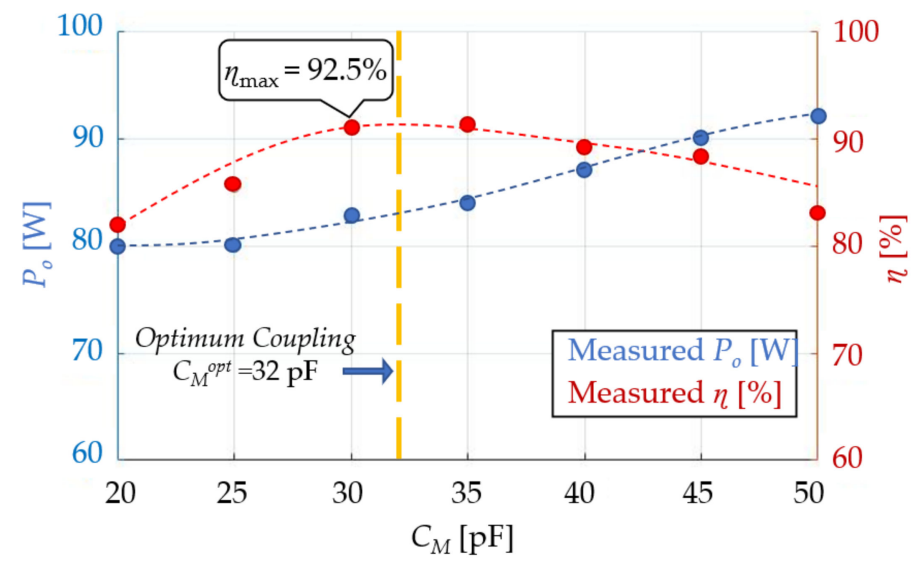

Figure 15. Experimental measurement of DC-AC conversion efficiency and output power at various $C_{M}$ values, where the blue line is the output power $P_{O}$ and the red line is the efficiency $\eta$.

In Table 5, the comparison in terms of output power, efficiency, operating frequency, and capacitive coupling between Class-E circuits available in the literature is shown.

Table 5. Comparison between literature systems.

\begin{tabular}{ccccc}
\hline Parameter & Output Power & Frequency & Efficiency & $\begin{array}{c}\text { Capacitive } \\
\text { Coupling }\end{array}$ \\
\hline$[24]$ & $20 \mathrm{~W}$ & $6.78 \mathrm{MHz}$ & $80 \%$ & $5.8 \mathrm{pF}$ \\
{$[25]$} & $1.7 \mathrm{~W}$ & $1 \mathrm{MHz}$ & $75 \%$ & $112 \mathrm{pF}$ \\
{$[26]$} & $5 \mathrm{~W}$ & $13.56 \mathrm{MHz}$ & $95 \%$ & $176 \mathrm{pF}$ \\
{$[27]$} & $3 \mathrm{~W}$ & $6.78 \mathrm{MHz}$ & $85 \%$ & $940 \mathrm{pF}$ \\
{$[28]$} & $360 \mathrm{~mW}$ & $2 \mathrm{MHz}$ & - & $250 \mathrm{pF}$ \\
{$[29]$} & $10 \mathrm{~W}$ & $1 \mathrm{MHz}$ & $93.4 \%$ & $350 \mathrm{pF}$ \\
{$[30]$} & $9.45 \mathrm{~W}$ & $1 \mathrm{MHz}$ & $98.4 \%$ & $2.20 \mathrm{nF}$ \\
Proposed & $83.5 \mathrm{~W}$ & $100 \mathrm{kHz}$ & $92.3 \%$ & $32 \mathrm{pF}$ \\
\hline
\end{tabular}

As shown, the proposed solution allows the increase of the transferred power operating at reduced switching frequency despite the low capacitive coupling.

\section{Conclusions}

This paper presents a complete analysis and the design procedure of the CWPT system based on a Class-E inverter. The analysis is focused on the coupling capacitance and its effects on the design constraints. It has been shown that the inverter satisfies both ZVS 
and ZDS conditions at a selected optimum coupling capacitance $C_{M}{ }^{\text {opt }}$ and satisfies ZVS conditions for $0<C_{M}<C_{M}$ opt, yielding a high conversion efficiency. The expressions for the inverter current and voltages have been determined as functions of the coupling capacitance $C_{M}$, so that the converter behavior also under misalignment between plates is predicted. Simulations and experimental results have been provided to validate the theoretical derivations.

Using the results of this paper, CWPT Class-E inverters can be designed for applications with fixed or variable coupling coefficient at any fixed load impedance. Additionally, thanks to the LC compensation, the operation at a lower frequency is allowed. This feature is obtained through a simpler control strategy with reduced switching losses and high quality of output waveforms (low THD). Therefore, compared with the similar experimental setup available in the literature, the proposed system is characterized by a higher output power transfer and a lower switching frequency.

Lower switching frequency operation allows controlling the system using controllers with low computational capabilities, which can be a useful feature for low-cost applications.

Furthermore, it operates at a lower frequency, leading to core losses reduction. On the other hand, this solution is useful for those applications where the optimization of the dimension and weight of the inverter is not of primary importance.

Practical applications of the considered CWPT circuit are in a wide variety of areas, including wireless power charging, induction heating, wireless-charged biomedical transplants, DC-DC power conversion, and DC-AC power inversion.

As future development, the performance of the DC-AC inverter using different four plates structures will be evaluated. A comparison between different structure solutions in terms of horizontal and vertical misalignment will be studied. Additionally, an extensive analysis of the power losses in the circuit will be evaluated, placing attention on the MOSFET losses and the losses due to parasitic components.

Author Contributions: Conceptualization: Y.-H.W., F.C., A.R., S.M., and D.C.; validation: Y.-H.W., and F.C.; writing-original draft preparation: F.C.; writing-review and editing: F.C., A.R., and S.M.; visualization: Y.-H.W., F.C., A.R., S.M., and D.C.; supervision: A.R., S.M., and D.C.; project administration: Y.-H.W., F.C., A.R., S.M., and D.C. All authors have read and agreed to the published version of the manuscript.

Funding: This work was supported by the Ministry of Science and Technology of Taiwan, R.O.C. with grant number MOST-108-2221-E-606-015.

Institutional Review Board Statement: Not applicable.

Informed Consent Statement: Informed consent was obtained from all subjects involved in the study.

Data Availability Statement: Conceptualization, Y.W., F.C., A.R., S.M., and D.C.; validation, Y.W., F.C.; writing-original draft preparation, F.C.; writing-review and editing, F.C., A.R., and S.M.; visualization, Y.W., F.C., A.R., S.M. and D.C..; supervision, A.R., S.M. and D.C.; project administration, Y.W., F.C., A.R., S.M., and D.C. All authors have read and agreed to the published version of the manuscript.

Conflicts of Interest: The authors declare no conflict of interest.

\section{References}

1. Schormans, M.; Valente, V.; Demosthenous, A. Correction to Practical Inductive Link Design for Biomedical Wireless Power Transfer: A Tutorial. IEEE Trans. Biomed. Circuits Syst. 2019, 13, 592. [CrossRef] [PubMed]

2. Covic, G.A.; Boys, J.T. Modern Trends in Inductive Power Transfer for Transportation Applications. IEEE J. Emerg. Sel. Top. Power Electron. 2013, 1, 28-41. [CrossRef]

3. Corti, F.; Reatti, A.; Pierini, M.; Barbieri, R.; Berzi, L.; Nepote, A.; De La Pierre, P. A Low-Cost Secondary-Side Controlled Electric Vehicle Wireless Charging System using a Full-Active Rectifier. In Proceedings of the 2018 International Conference of Electrical and Electronic Technologies for Automotive, Milan, Italy, 9-11 July 2018; pp. 1-6.

4. Carobolante, F.; Menegoli, P.; Marino, F.A.; Jeong, N.S. A Novel Charger Architecture for Resonant Wireless Power Transfer. IEEE J. Emerg. Sel. Top. Power Electron. 2018, 6, 571-580. [CrossRef] 
5. Zaman, H.U.; Islam, T.; Hasan, K.S.; Antora, R.K. Mobile phone to mobile phone wireless power transfer. In Proceedings of the 2015 International Conference on Advances in Electrical Engineering (ICAEE), Dhaka, Bangladesh, 17-19 December 2015; pp. 206-209.

6. Liu, Y.; Li, B.; Huang, M.; Chen, Z.; Zhang, X. An Overview of Regulation Topologies in Resonant Wireless Power Transfer Systems for Consumer Electronics or Bio-Implants. Energies 2018, 11, 1737. [CrossRef]

7. Tampubolon, M.; Pamungkas, L.; Chiu, H.-J.; Liu, Y.-C.; Hsieh, Y. Dynamic Wireless Power Transfer for Logistic Robots. Energies 2018, 11, 527. [CrossRef]

8. Xie, L.; Shi, Y.; Hou, Y.T.; Lou, A. Wireless power transfer and applications to sensor networks. IEEE Wirel. Commun. 2013, 20, 140-145. [CrossRef]

9. Bartolini, A.; Corti, F.; Reatti, A.; Ciani, L.; Grasso, F.; Kazimierczuk, M.K. Analysis and Design of Stand-Alone Photovoltaic System for precision agriculture network of sensors. In Proceedings of the 2020 IEEE International Conference on Environment and Electrical Engineering and 2020 IEEE Industrial and Commercial Power Systems Europe (EEEIC/I\&CPS Europe), Madrid, Spain, 9-12 June 2020; pp. 1-5.

10. Hui, S.Y.R.; Zhong, W.; Lee, C.K. A Critical Review of Recent Progress in Mid-Range Wireless Power Transfer. IEEE Trans. Power Electron. 2014, 29, 4500-4511. [CrossRef]

11. Dai, J.; Ludois, D.C. A Survey of Wireless Power Transfer and a Critical Comparison of Inductive and Capacitive Coupling for Small Gap Applications. IEEE Trans. Power Electron. 2015, 30, 6017-6029. [CrossRef]

12. Minnaert, B.; Stevens, N. Maximizing the Power Transfer for a Mixed Inductive and Capacitive Wireless Power Transfer System. In Proceedings of the 2018 IEEE Wireless Power Transfer Conference (WPTC), Montreal, QC, Canada, 3-7 June 2018; pp. 1-4.

13. Yi, K. Capacitive Coupling Wireless Power Transfer with Quasi-LLC Resonant Converter Using Electric Vehicles' Windows. Electronics 2020, 9, 676. [CrossRef]

14. Funato, H.; Kobayashi, H.; Kitabayashi, T. Analysis of transfer power of capacitive power transfer system. In Proceedings of the 2013 IEEE 10th International Conference on Power Electronics and Drive Systems (PEDS), Kitakyushu, Japan, 22-25 April 2013; pp. $1015-1020$.

15. Mazli, M.S.; Fauzi, W.N.N.W.; Khan, S.; Aznan, K.A.; Nataraj, C.; Adam, I.; Kadir, K.; Ahmed, M.M.; Yaacob, M. Inductive \& Capacitive Wireless Power Transfer System. In Proceedings of the 2018 7th International Conference on Computer and Communication Engineering (ICCCE), Kuala Lumpur, Malaysia, 19-20 September 2018; pp. 307-312.

16. Pagano, R.; Abedinpour, S.; Raciti, A.; Musumeci, S. Efficiency optimization of an integrated wireless power transfer system by a genetic algorithm. In Proceedings of the 2016 IEEE Applied Power Electronics Conference and Exposition (APEC), Long Beach, CA, USA, 20-24 March 2016; pp. 3669-3676.

17. Pagano, R.; Abedinpour, S.; Raciti, A.; Musumeci, S. Modeling of planar coils for wireless power transfer systems including substrate effects. In Proceedings of the IECON 2016-42nd Annual Conference of the IEEE Industrial Electronics Society, Florence, Italy, 23-26 October 2016; pp. 1129-1136.

18. Shenai, K. Future Prospects of Widebandgap (WBG) Semiconductor Power Switching Devices. IEEE Trans. Electron Devices 2014, 62, 248-257. [CrossRef]

19. Liu, K.-H.; Lee, F. Zero-voltage switching technique in DC/DC converters. IEEE Trans. Power Electron. 1990, 5, 293-304. [CrossRef]

20. Ogi, Y.; Ebihara, F.; Wei, X.; Sekiya, H. A Novel Circuit Topology and Its Design for Class-E2 DC-DC Converter. In Proceedings of the 2019 IEEE Energy Conversion Congress and Exposition (ECCE), Baltimore, MD, USA, 29 September-3 October 2019; pp. 1256-1260.

21. Aldhaher, S.; Luk, P.C.; Bati, A.F.; Whidborne, J.F. Wireless Power Transfer Using Class E Inverter With Saturable DC-Feed Inductor. IEEE Trans. Ind. Appl. 2014, 50, 2710-2718. [CrossRef]

22. Li, Y.-F.; Sue, S.-M. Exactly analysis of ZVS behavior for class E inverter with resonant components varying. In Proceedings of the 2011 6th IEEE Conference on Industrial Electronics and Applications, Beijing, China, 21-23 June 2011; pp. 1245-1250.

23. Dong, G.; Liangzong, H.; Bing, C.; Han, G. An Active Clamping Strategy for Class-E Inverter in Wireless Power Transfer System. In Proceedings of the 2019 IEEE International Symposium on Predictive Control of Electrical Drives and Power Electronics (PRECEDE), Quanzhou, China, 1 May-2 June 2019; pp. 1-5. [CrossRef]

24. Ahmad, S.; Muharam, A.; Hattori, R. Rotary Capacitive Power Transfer with Class-E Inverter And Balun Circuit. In Proceedings of the 2020 IEEE PELS Workshop on Emerging Technologies: Wireless Power Transfer (WoW), Seoul, Korea, 15-19 November 2020; pp. 330-333.

25. Ueda, H.; Koizumi, H. Class-E2 DC-DC Converter With Basic Class-E Inverter and Class-E ZCS Rectifier for Capacitive Power Transfer. IEEE Trans. Circuits Syst. II Express Briefs 2020, 67, 941-945. [CrossRef]

26. Chokkalingam, B.; Padmanaban, S.; Leonowicz, Z.M. Class E Power Amplifier Design and Optimization for the Capacitive Coupled Wireless Power Transfer System in Biomedical Implants. Energies 2017, 10, 1409.

27. Domingos, F.C.; Freitas, S.V.D.C.D.; Mousavi, P. Capacitive Power Transfer based on Compensation Circuit for Class E Resonant Full-Wave Rectifier. In Proceedings of the 2018 IEEE Wireless Power Transfer Conference (WPTC), Montreal, QC, Canada, 3-7 June 2018; pp. 1-4.

28. Huang, L.; Hu, A.P. Power Flow Control of Capacitive Power Transfer by Soft Switching of Extra Capacitors in Class E Converter. In Proceedings of the 2018 IEEE 4th Southern Power Electronics Conference (SPEC), Singapore, 10-13 December 2018; pp. 1-5. 
29. Yusop, Y.; Saat, S.; Husin, H.; Nguang, S.K.; Hindustan, I. Analysis of Class-E LC Capacitive Power Transfer System. Energy Proc. 2016, 100, 287-290. [CrossRef]

30. Yusop, Y.; Saat, S.; Husin, H.; Hindustan, I.; Rahman, F.A.; Kamarudin, K.; Nguang, S.K. A Study of Capacitive Power Transfer Using Class-E Resonant Inverter. Asian J. Sci. Res. 2016, 9, 258-265. [CrossRef]

31. Kazimierczuk, M.; Bui, X. Class-E DC/DC converters with a capacitive impedance inverter. IEEE Trans. Ind. Electron. 1989, 36, 425-433. [CrossRef]

32. Ayachit, A.; Corti, F.; Reatti, A.; Kazimierczuk, M.K. Zero-voltage switching operation of transformer Class-E inverter at any coupling coeffi-cient. IEEE Trans. Ind. Electron. 2019, 66, 1809-1819. [CrossRef]

33. Corti, F.; Grasso, F.; Reatti, A.; Ayachit, A.; Saini, D.K.; Kazimierczuk, M.K. Design of class-E ZVS inverter with loosely-coupled transformer at fixed coupling coefficient. In Proceedings of the IECON 2016-42nd Annual Conference of the IEEE Industrial Electronics Society, Florence, Italy, 23-26 October 2016; pp. 5627-5632.

34. Zhang, H.; Lu, F.; Hofmann, H.; Mi, C. A loosely coupled capacitive power transfer system with LC compensation circuit topology. In Proceedings of the 2016 IEEE Energy Conversion Congress and Exposition (ECCE), Milwaukee, WI, USA, 18-22 September 2016; pp. 1-5.

35. Kazimierczuk, M.K.; Czarkowski, D. Resonant Power Converters, 2nd ed.; Wiley Interscience: Hoboken, NJ, USA, 2012.

36. Ayachit, A.; Saini, D.K.; Kazimierczuk, M.K.; Reatti, A. Design of choke inductor in Class-E ZVS power amplifier. In Proceedings of the IECON 2016-42nd Annual Conference of the IEEE Industrial Electronics Society, Florence, Italy, 23-26 October 2016; pp. 5621-5626.

37. Raciti, A.; Rizzo, S.A.; Salerno, N.; Susinni, G.; Scollo, R.; Scuto, A.; Musumeci, S.; Armando, E. Modeling of the Power Losses due to Coss in SJ MOSFETs Submitted to ZVS: Identification of the Passive Parameters by a Genetic Algorithm. In Proceedings of the IECON 2018 - 44th Annual Conference of the IEEE Industrial Electronics Society, Washington, DC, USA, 21-23 October 2018; pp. 1321-1326.

38. Bojoi, R.; Fusillo, F.; Raciti, A.; Musumeci, S.; Scrimizzi, F.; Rizzo, S. Full-Bridge DC-DC Power Converter for Telecom applications with Advanced Trench Gate MOSFETs. In Proceedings of the 2018 IEEE International Telecommunications Energy Conference (INTELEC), Turin, Italy, 7-11 October 2018; pp. 1-7. [CrossRef]

39. Kessler, D.J.; Kazimierczuk, M.K. Power losses and efficiency of class-E power amplifier at any duty ratio. IEEE Trans. Circuits Syst. I Regul. Pap. 2004, 51, 1675-1689. [CrossRef] 